\title{
Lean: it's not rocket science, it's work science
}

Joanne Gaudet* and France Bergeron*

\section{Abstract}

The main goal of this paper is to deepen understanding for Lean as a science of work based on flow. Flow here is the process of energy moving through a system. The paper first presents the three main elements of a science. It then deals with internal consistency for Lean as a scientific knowledge system with a need to discard the notion of 'truth'. Third, the paper delves into Lean as collaborative science. Finally, focus shifts to individual and team flow and how a Lean culture creates the conditions and relations for optimal individual and team flow for increased creativity and innovation. The authors conclude that a deeper understanding of Lean can help more organizations prosper.

(C) 2016 The authors (Joanne Gaudet and France Bergeron). For any use, the original work must be properly cited: Gaudet, J. and F. Bergeron. 2016. Lean: it's not rocket science, it's work science. uO Research. Pp. 1-11. http://ruor.uottawa.ca/bitstream/10393/35002/1/Lean\%2c\%20it\%e2\%80\%99s\%20not\%20rocket\%20science\%2c\%20it\%e2\%80 \%99s\%20work\%20science.2016.Gaudet.Bergeron.pdf

\section{Introduction}

The main goal of this paper is to deepen understanding for Lean as a science of work based on flow $^{1}$, in any context, whether in manufacturing, in government, in health care or at home. As long as there is work performed, implementation of Lean as science can increase efficiency, effectiveness, creativity, innovation and foster a learning culture. An organization that implements Lean as science has a Lean culture: shared language, values and practices ${ }^{2}$ of scientifically improving work, every day.

More specifically, Lean is framed as an applied ${ }^{3}$ and collaborative science. Everyone in an organization, as equals, collaborates to optimize the flow of value to clients by co-identifying and analyzing problems (barriers to flow), co-constructing and testing countermeasures ${ }^{4}$, coimproving and containing flow every day and sharing scientific explanations (about flow and barriers to flow). Some of the scientific tools and methods used in Lean to see, measure and optimize flow include experimentation (Plan-Do-Study-Adjust cycle), visual management, standardization, mapping and ethnography (observation where value is created, Gemba).

Flow is the process of energy (i.e. work as intellectual and/or physical effort, machine and electronic effort) moving through a system. Because Lean is an applied science, organizations (as systems) that live a Lean culture hold a common deterministic goal: optimize flow by using less and less energy, while maximizing value delivery to clients.

\footnotetext{
*Alpen Path Solutions, Ottawa, Ontario. email: info [at] alpenpathsolutions.com.

${ }^{1}$ See focus on flow and including employees and management in Harada (2015).

${ }^{2}$ See science as culture in Knorr Cetina (1999); Lean as science in Gaudet (2013).

${ }^{3}$ An applied science refers to a science that has immediate real-world applications whereas basic or theoretical science has no immediate real-world application.

${ }^{4}$ In Lean, countermeasure is used instead of 'solution' to acknowledge the potential for uncertainty and surprise (related on science in Gross, 2010; Gaudet, 2015).
} 
Lean is based on the Toyota Production System established at the Toyota car manufacturer in Japan some 70 years ago. The term Lean was first coined by John Krafcik to differentiate mass production from a production that "... is lean because it uses less of everything " where "Lean producers [...] set their sights explicitly on perfection". Perfection is "continually declining costs, zero defects, zero inventories, and endless product variety. ${ }^{5}$ Key to aiming for perfection at Toyota is allowing employees to control their own work by pushing problem solving and decision-making to the lowest level possible ${ }^{6}$.

The paper builds on science studies, on flow studies (in engineering, physics, chemistry, biomedicine, sociology, psychology and neurosciences), on Lean research in a wide range of public and private sector organizations including in manufacturing, health care and at all levels of government, and on our experience as Lean practitioners and coaches.

The paper unfolds in four parts. First, we present the three main elements of any science and then hone in on the elements specifically for Lean. Second, we deal with internal consistency for Lean as a scientific knowledge system, the foundation for Lean as collaborative science. Third, we touch on collaborative science. Finally, we explore individual and team flow and how a Lean culture creates the conditions and relations for optimal individual and team flow for increased motivation, creativity and innovation.

\section{Elements of science}

Within the natural sciences or the social sciences, contemporary science holds three main elements $^{7}$ : (a) a careful construction of what is being studied, (b) the use of rigorous methods and tools, and (c) the dissemination of scientific explanations. Following is an overview for each and specifics for Lean as science.

\section{a) Careful construction of what is studied}

In science, what is being studied (the scientific object of study) must reflect a core understanding for any given phenomenon and hold the least assumptions possible. An object of study must hold the least assumptions possible so that scientific study for an object yields insights that are not owing to chance or are inconsistent and unreliable.

For example, respiration as a common experience process or self-evident object of study can be summed up as follows: breathing air into, and expiring air out of a set of lungs via a nose or a mouth. Assumptions include: (a) the need for a nose and mouth, (b) the need for one set of lungs, and (c) air as the only element that sustains respiration. Here it seems natural that only organisms (i.e. mammals) with a nose, mouth and a set of lungs engage in respiration with air. The understanding does not provide insights into the function(s) of respiration, how it could have come to be or extend beyond mammals to other organisms.

Based on the apparent naturalness of respiration in this common experience process, other types of respiration might appear 'unnatural'. Fish that respire in aquatic environment and

\footnotetext{
${ }^{5}$ Womack et al. (1990: 13-14).

${ }^{6}$ Womack et al. (1990); Spear and Bowen (1999).

${ }^{7}$ Related in Bourdieu et al. (1968); Gaudet (2014); Dawes (2009).
} 
insects with no lungs would not engage in purportedly 'natural' respiration.

The above can be contrasted with a scientific understanding of respiration: the intake of oxygen, output of carbon dioxide and creation of energy by organisms (VetSci, 2010). This deeper understanding does not single out one type of respiration as purportedly 'natural', provides insights into function(s) of respiration and includes organisms other than mammals that engage in respiration. No longer excluded as 'unnatural' are: fish that respire in aquatic environments, insects that do not possess lungs but have spiracles on their exteriors that work as 'valve like openings' to intake oxygen, amphibians that can engage in respiration through their skin in addition to having lungs and birds that can possess three sets of lungs (VetSci, 2010). The scientific object proposes analogy for respiration across what on the surface might appear as unrelated organisms and dynamics.

Because it is essential not to focus on superficial and self-evident commonalities of phenomena, scientists spend a lot of time constructing deep analogies that tie phenomena together ${ }^{8}$. This way they can gain insight into, and in applied sciences, gain control over phenomena. In the case of an applied science like Lean, removing assumptions is critical to foster rigorous continuous improvement in real-world experiments.

In Lean, what is being studied is flow ${ }^{9}$. It is not surprising that engineers at Toyota focused on flow because flow is studied extensively in engineering as well as in physics, chemistry, biomedicine, sociology, psychology and neurosciences. Flow here is the process of energy (work as intellectual and/or physical effort, machine and electronic effort) moving through a system. There are two key elements in the definition. First, it is not ' $w$ hat' is being delivered that is studied for flow, such as permits, surgery, bicycles or legal advice. Rather, what is being looked at is the flow of energy expended to deliver. Flow for work can be optimized regardless of where work is performed and what is being delivered. Second, flow can only be fully understood from a system perspective.

For example, the process of (a) a government agency issuing a license to a citizen, (b) an accounting firm creating a financial report for a business, or (c) a restaurant producing a hamburger for a customer involves the flow of intellectual, physical and machine/electronic energy. The energy must be aligned with organizational priorities/goals and be optimized (using the least energy) to deliver what the client values.

Each and every employee and executive in a Lean organization becomes familiar with work as flow and learns how to scientifically measure and share flow data in order to solve flow problems, every day. Because Lean is an applied science, the main goal is to optimize flow (use less and less energy) by minimizing disruptions to flow from a system perspective, to maximize value for the client.

To optimize flow, all levels in an organization are actively engaged:

${ }^{8}$ Bourdieu et al. (1968); examples of non-scientific objects of study in Biagioli (2002), Hirschauer (2010) and Gaudet (2014).

${ }^{9}$ Nonaka et al., (2015); Ohno (1988); Harada (2015). 
- Management: aligns flow with organizational goals, contains flow and removes constraints to flow by limiting and by adjusting priorities, and ensures standard work is continually revised for optimal flow (using strategy deployment, leader standard work, observation where value is created, Gemba).

- Employees: ensure flow is visible in real-time so that it can be continuously and consistently measured and optimized (using visual management, standard work). This means that in a Lean workplace:

$\checkmark$ "It's easy to see how much effort a person is putting into work.

$\checkmark$ Everyone can see the results of the work.

$\checkmark$ Everyone can see the results of changes and how they affect the output."10 This allows a Lean organization to evaluate performance not only on the delivery of results, but on the optimization of processes from a system perspective in order to achieve and sustain such results.

In contrast, we argue that by defining Lean as the elimination of waste ${ }^{11}$, organizations focus improvement efforts on the wrong object of study and this has led to a high level of Lean implementation failure ${ }^{12}$. Lean based on waste promotes waste chasing, fails to see the system by delegating waste chasing to front lines and loses sight that waste in one context might be value in another ${ }^{13}$. Waste is full of assumptions, precludes system thinking and is therefore not a scientific object of study for work. Waste is only one type of disruptor to flow. A culture of command-and-control and blame, chaos and too many priorities, for example, also disrupt flow and must be addressed in a Lean transformation ${ }^{14}$.

\section{b) Rigorous methods and tools ${ }^{15}$}

The second element of contemporary science is the use of rigorous methods and tools by scientists. For a method or a tool to be considered scientific, it must empirically capture what is being observed and more than one scientist should be able to construct what are deemed as acceptable data in a scientific community ${ }^{16}$. Methods frequently used by scientists include experimentation, in situ observation and textual analysis. Scientists use tools to see their object of study (i.e. Magnetic Resonance Imaging (MRI), microscopes, telescopes, surveys and interviews).

${ }^{10}$ Harada (2015:100).

${ }^{11}$ Waste in Lean refers to activities that are considered non-value adding from a client's perspective.

${ }^{12}$ See related discussion of Lean implementation failure in government in Radnor (2014).

${ }^{13}$ We use nuclear regulation as an example. Citizens can value additional reviews for nuclear regulation but would not necessarily value additional reviews for a temporary employee HR staffing process. Reviews are typically classified as 'waste', but context is key to understanding if a review is deemed as waste or value.

${ }^{14}$ See related in Martin (2012).

${ }^{15}$ We do not elaborate on research design in this paper. Lean uses mostly mixed methods (quantitative and qualitative) with single case study designs.

${ }^{16}$ Note: not necessarily identical data given the social construction of knowledge. 
In Lean organizations, methods and tools are frequently collaborative (see knowledge and collaboration below). This means that multiple individuals can co-use a method or a tool, collaborate in the construction of problem definitions, see and co-construct flow data with a goal to help optimize flow of value to clients.

A scientific thinking culture in a Lean organization involves coaching and developing employees to take on a scientific mind-set, including ${ }^{17}$ : a logical thinking process; eliciting different viewpoints (social construction of the problem) on hindrances to flow; synthesis, distillation and visualization of flow data; and, maintaining a systems viewpoint that does not lose focus of how flow optimization relates to broader priorities/goals.

Scientific tools and methods used in Lean include:

- strategy deployment (Hoshin Kanri)

- experimentation (Plan-Do-Study-Adjust cycle)

- ethnography (observation where value is created, Gemba walk)

- standard work (for employees and leaders)

- visual management (i.e. boards, visual signals, mapping flow of processes)

- $5 \mathrm{~S}$ (workspace organization and management)

- 5 Whys (root cause analysis)

- Error proofing

\section{c) Scientific explanation}

The third element of contemporary science is the scientific explanation. Since at least the $17^{\text {th }}$ century, scientists have increasingly shared their empirically based scientific explanations and this sharing fosters a learning culture worldwide. What is deemed as a scientific explanation changes from one scientific discipline to another and also over time.

Generally, in order to be deemed as scientific in the $21^{\text {st }}$ Century, an explanation typically includes details on testability, refers to mechanisms similar to those already known, follows previous research, is simple, is informative, and proposes as few new ontological entities as is necessary ${ }^{18}$. Ontological entities refer to 'what exists' ${ }^{19}$.

Scientific explanations in Lean can take the shape of an $A 3^{20}$ or a case study ${ }^{21,22}$ shared in an accessible area to promote learning.

${ }^{17}$ Adapted from Sobek II and Smalley (2008:12).

${ }^{18}$ Dawes (2009).

${ }^{19}$ In work science for example, 'goblins in an information technology system' would not qualify as scientifically acceptable ontological entities.

${ }^{20}$ The A3 report is "a standard method for summarizing problem solving exercises, status reports, and planning exercises" (Lean Enterprise Institute, 2008:1); see Shook (2010).

${ }^{21}$ Case studies in science: Yin (2003); Ragin and Becker (1992); Compton-Lilly (2013).

22 Lean case studies are constructed for lengthier process improvement exercises, such as process improvement events, and are published for broader learning. 


\section{Knowledge in a Lean Culture}

In addition to meeting the three elements of a science and to ensure a rigorous and sustainable organizational transformation, Lean must also demonstrate internal consistency ${ }^{23}$ as a scientific knowledge system. In science studies, this falls under the study of knowledge (epistemology) and of what exists (ontology). The epistemology and ontology of any science and its research must be internally consistent.

\section{Epistemology}

Delving into the study of knowledge in Lean, there are two relevant schools of thought: knowledge as a social construction (social constructivism, with knowledge shaped by multiple actors, as equals) which lies at one end of a spectrum and knowledge as 'truth' (positivism, with knowledge as objective by experts) which lies further away ${ }^{24}$.

Lean is frequently stereotyped as yielding ' $\mathrm{truth}^{25}$, based mostly on its use of the experimental method which in itself is a stereotype of science. This is where the discourse on Lean as a scientific knowledge system is dissonant. Lean can only be deemed rigorous and scientific when, and only when, the three elements of a science (above) are respected, not when only one of several tools and methods is cited (i.e. experimental method).

Lean explicitly recognizes individuals working where value is created (at the Gemba) as contributing contextual knowledge tied with their role as unique knowledge producers. Knowledge in Lean is socially constructed by all as equals and therefore cannot be framed as 'truth'. When the experimental method is used, it is not to find "the" perfect truth, but to socially construct the most appropriate countermeasure, in context ${ }^{26}$.

Tied with internal consistency for knowledge, all relations in Lean must be transparent and open (i.e. each process has an identified and publicly-known owner; each A3 has an identified and publicly-known owner). Why? In Lean as science, knowledge is socially constructed and cannot remain unattributed to a person as an individual knowledge producer. Trust in knowledge is tied to knowing the individual ${ }^{27}$ who constructs or the individuals in the team that co-construct knowledge on work.

Consequently, so-called Lean belt systems are not internally consistent with Lean because they promote hierarchies of experts who typically 'do' Lean to others ${ }^{28}$. In Lean organizations, everyone 'is Lean' - or more precisely, is a scientist of work - and collaborates to scientifically articulate problems, gathers and analyzes data, to finally test and implement countermeasures to continuously optimize flow.

${ }^{23}$ Pascale (2011); Flyvbjerg (2001); Walker (2004).

${ }^{24}$ See related for nursing in Walker (2004); Pascale (2011).

${ }^{25}$ Examples: Nonaka et al. (2015), Spear and Bowen (1999), Sobek II and Smalley (2008).

${ }^{26}$ See related in Gaudet (2015).

${ }^{27}$ Simmel (1906).

${ }^{28}$ Hohmann (2014). 


\section{Ontology}

Lean achieves greatest internal consistency when moved away from 'truth'. Social construction means that ontologically, knowledge about work does not simply 'exist out there' as truth, ready to be 'discovered' or arbitrarily imposed by an external 'expert' such as a supervisor (command-and-control) or a so-called Lean belt expert. Rather, those who perform work constantly shape work knowledge, in context.

Social construction is perhaps one of the most powerful aspects of Lean because it acknowledges that those closest to work are best positioned to construct knowledge on optimal flow whereas management is best positioned to help contain flow, remove constraints to flow and ensure flow aligns to organizational goals. This means allowing employees to control their own work by pushing problem solving and decision-making to the lowest level possible $^{29}$. In Lean organizations, workers are developed as trusted scientists with recognized expertise in their respective areas. There are no 'experts' in the science of work, but there can be 'experts' in the content of work (i.e. medical doctor, communications officer, teacher, receptionist, and lawyer).

\section{Collaborative Science}

The previous section is pivotal to understanding Lean as collaborative science ${ }^{30}$. In collaborative science there are no 'expert' to 'non-expert' relations. This is in contrast to participatory science where 'non-experts' might be able to contribute to science by gathering data, but only 'experts' are allowed to analyze data ${ }^{31}$. In collaborative science, everyone's contribution is respected and deemed as valuable and equal. This reinforces the internal consistency of Lean as science with everyone equal in the social construction of knowledge. At their respective levels, workers as scientists collaborate to articulate problems, gather and analyze data and develop, test and implement countermeasures to continuously optimize flow.

\section{Individual and team flow}

Up to this point, when referring to flow as the process of energy moving through a system, the system was the organization. In this section, the system is narrowed to individuals and teams (within an organization). Extensive research on flow experience ${ }^{32}$ at the individual and team levels sheds light on the increase in motivation, learning, creativity and innovation in extreme sports, in everyday life, in science, and in business with companies such as Toyota ${ }^{33}$.

In optimal flow for individuals and for teams, energy (tied with neurochemical, anatomical and

${ }^{29}$ Harada (2015); Spear and Bowen (1999); Womack et al. (1991).

${ }^{30}$ Collaborative science is used in many disciplines including medical science, biological science and in environmental sciences (i.e. Geissler, 2013; typology in Haklay, 2013).

${ }^{31}$ Participatory science is a model frequently used in citizen science (Haklay, 2013).

${ }^{32}$ Adee (2012); Cseh et al. (2016); Csikszentmihalyi (1997); Kotler (2014), Kadosh (2013); van den Hout et al. (2016).

${ }^{33}$ Other companies cited include Ericsson and Patagonia (Kotler, 2014). 
physiological changes ${ }^{34}$ ) intensifies focus on the present. A central flow characteristic "... is intense experiential involvement in moment-to-moment activity: attention is fully invested in the task at hand, and the person functions at his or her fullest capacity" ${ }^{35}$. Chemicals released into the brain during flow are rewarding and highly addictive, therefore people are motivated to re-engage ${ }^{36}$ in activities in which they are in flow. Of special interest for organizations is that while in flow, individuals and teams achieve better performance ${ }^{37}$, including accelerated problem solving.

How can organizations create conditions and relations for flow? There are several triggers or precursors $^{38}$ to individual and team flow. The triggers ensure that attention is heightened and remains in the present. We list a few triggers with details specific to Lean in parentheses.

- High consequences or risks (there is always the potential for an experiment to fail and employees are responsible and accountable for problem solving)

- Immediate and constant feedback (problems are detected in real-time with visual management; standard work; use of post-its during group sessions engage more senses, help stick to the present and elicit immediate feedback from other participants)

- Concentration (controlling flow means that in Lean there is reduced multitasking; meetings are reduced to a minimum; management contains priorities to a few at a time, i.e. stop starting, start finishing)

- Balanced challenge to skills ratio (Lean employees control their own work with problem solving and decision-making at their level, with accountability. This means that when they encounter problems, they are allowed and challenged to analyze and counter problems, alone or collaboratively)

- Shared and clear goals (aligned organizationally to deliver value to clients)

- A feeling of personal control over a situation where reward is intrinsic (Lean employees control their own work with problem solving and decision-making at their level. Lean organizations do not attempt to 'motivate' employees with external rewards. The ability to engage in problem solving, transparent for all to see, at one's own level is intrinsically motivating)

- Blending egos (team flow, as a group of equals in Lean there are no ranks, no single individual is allowed to dominate a group)

- Mutual commitment (team flow, everyone is expected to pull their weight, individuals hold each other to account)

- Always say yes (team flow, in Lean brainstorming, never stop the flow of ideas with arguments. Individuals increase momentum and constructively build on each other's ideas by saying 'what if..." in the affirmative, instead of 'no')

${ }^{34}$ Csikszentmihalyi (1997); Kotler (2014).

${ }^{35}$ van den Hout et al. (2016).

${ }^{36}$ For scientists, addictive is termed 'autotelic': someone deems that an activity in which they engage in is rewarding for its own sake, Csikszentmihalyi (1997); Kotler (2014).

${ }^{37}$ Kotler (2014); Cseh et al. (2016); van den Hout et al. (2016)

${ }^{38}$ Csikszentmihalyi (1997); Kotler (2014); van den Hout et al. (2016). 
In light of these insights into individual and team flow, Lean fosters ideal conditions and relations for flow states by sustaining a community of work scientists.

\section{Concluding remarks}

It is not surprising that Toyota has been developing, implementing and prospering with the Toyota Production System for over 70 years. As elaborated in this paper, Lean, based on the Toyota Production System, is an applied collaborative science of work. Evidence-based, Lean delivers value while fostering a motivated and engaged workforce. With a motivated and engaged scientific workforce focused on flow, Lean leads to increased efficiency, effectiveness, creativity and innovation and nurtures a learning culture. Lean is the only management approach that an organization will ever need, much like at Toyota.

What is surprising, however, is that individuals and organizations can be reluctant to adopt Lean or fail in their attempts to adopt it. Perhaps if Lean is more systematically understood and deployed as science instead of a management approach du jour or pseudo-science focused on tools, belts and waste, more organizations will prosper with Lean ${ }^{39}$.

We challenge: (1) organizations to develop a community of collaborative scientists of work, and (2) researchers to carefully construct the object of study for Lean. In doing so, researcher efforts can further understanding for Lean and provide organizations with much needed insights that will allow them to judiciously expend energy during a Lean transformation. Insightful research will also prevent organizations from falling prey to consultants seeking to profit from ill-founded and unsustainable short-term focused tool and belt expert-based transformations ${ }^{39}$.

\section{References}

Adee, S. (2012). "Zap your brain into the zone: Fast track to pure focus." New Scientist 2850: 1-6.

Biagioli, M. (2002). "From Book Censorship to Academic Peer Review." Emergences: Journal for the Study of Media \& Composite Cultures 12:11-45.

Bourdieu, P., et al. (1968). Le métier de sociologue: Livre I. Paris, École Pratique des Hautes Études, Mouton and Bordas.

Compton-Lilly, C. (2013). Case Studies. Reviewing Qualitative Research in the Social Sciences. A. A. Trainor and E. Graue. New York, Routledge: 54-65.

Cseh, G. M., et al. (2016). "Mental and perceptual feedback in the development of creative flow." Consciousness and Cognition 42: 150-161.

Dawes, G. W. (2009). Theism and Explanation. New York, Routledge.

Flyvbjerg, B. (October 2005-March 2006). "Social Science That Matters." Foresight Europe 2: 38-42.

\footnotetext{
${ }^{39}$ See limitations of tool-based deployment in Radnor (2013); see Hohmann (2014); see Harada (2015:133) on not creating a separate "Lean office".
} 
Gaudet, J. (2015). Unfolding the map: Making knowledge and ignorance mobilization dynamics visible in science evaluation and policymaking. The International Handbook of Ignorance. M. Gross and L. McGoey. New York, Routledge: 318-327.

Gaudet, J. (2014). Investigating journal peer review as scientific object of study: unabridged version - Part I. uO Research. 1-24.

Gaudet, J. (2013). "It takes two to tango: knowledge mobilisation and ignorance mobilisation in science research." Prometheus: Critical Studies in Innovation 31(3): 169-187.

Geissler, P. W. (2013). "Public secrets in public health: Knowing not to know while making scientific knowledge." American Ethnologist 40(1): 13-34.

Gross, M. (2010). Ignorance and Surprise: Science, Society and Ecological Design. Cambridge, The MIT Press.

Haklay, M. (2013). Citizen Science and Volunteered Geographic Information - overview and typology of participation. Crowdsourcing Geographic Knowledge: Volunteered Geographic Information (VGI) in Theory and Practice. D. Z. Sui, S. Elwood and M. F. Goodchild. Berlin, Springer: 105-122.

Harada, T. (2015). Management Lessons from Taiichi Ohno: What Every Leader can Learn from the Man Who Invented the Toyota Production System. New York, McGraw Hill Education.

Hirschauer, S. (2010). "Editorial Judgments: A Praxeology of 'Voting' in Peer Review." Social Studies of Science 40:71-103.

Hohmann, C. (2014). Lean Management: Outils, Méthodes, Retours d'Expériences, Questions/Réponses. Paris, Groupe Eyrolles.

Kadosh, R. C. (2013). "Using transcranial electrical stimulation to enhance cognitive functions in the typical and atypical brain." Translational Neuroscience 4(1): 20-33.

Knorr Cetina, K. (1999). Epistemic Cultures: How the Sciences Make Knowledge. Cambridge, Harvard University Press.

Kotler, S. (2014). The rise of superman: decoding the science of ultimate human performance. Boston, New Harvest, Houghton Mifflin Harcourt.

Lean Enterprise Institute (2008). Lean Lexicon: A Graphical Glossary for Lean Thinkers. $4^{\text {th }}$ Edition. Cambridge MA, Lean Enterprise Institute.

Luis, S. V. and E. Garcia-Verdugo, Eds. (2010). Chemical reactions and processes under flow conditions. RSC Green Chemistry Series. Cambridge, Royal Society of Chemistry.

Martin, K. (2012). The Outstanding Organization: Generate Business Results by Eliminating Chaos and Building the Foundation for Everyday Excellence. New York, McGraw Hill. 
Nonaka, I., et al. (2015). Managing flow: a process theory of the knowledge-based firm. New York, Palgrave Macmillan.

Ohno, T. (1988). Toyota Production System: Beyond large-scale production. Boca Raton, Taylor and Francis.

Pascale, C.-M. (2011). Cartographies of Knowledge: Exploring Qualitative Epistemologies. Los Angeles, SAGE.

Radnor, Z. and S. P. Osborne (2013). "Lean: A failed theory for public services?" Public Management Review 15(2): 265-687.

Ragin, C. C. and H. Becker, Eds. (1992). What is a Case? Exploring the Foundations of Social Inquiry. Cambridge, Cambridge University Press.

Shook, J. (2010). Managing to Learn. Using the A3 Management Process to Solve Problems, Gain Agreement, Mentor, and Lead. Cambridge, Lean Enterprise Institute.

Simmel, G. (1906). "The Sociology of Secrecy and of Secret Societies." American Journal of Sociology 11:441-498.

Sobek II, D. K. and A. Smalley (2008). Understanding A3 Thinking: A Critical Component of Toyota's PDCA Management System. Boca Raton, CRC Press.

Spear, S. and H. K. Bowen (1999). "Decoding the DNA of the Toyota Production System." Harvard Business Review September-October: 97-106.

van den Hout, J. J. J., et al. (2016). The Application of Team Flow Theory. Flow Experience: Empirical Research and Applications. L. Harmat, F. Ørsted Andersen, F. Ullén, J. Wright and G. Sadlo, Springer International: 233-243.

VetSci (2010). "Comparative Animal Respiration." Retrieved December 14, 2014, from http://vetsci.co.uk/2010/02/28/comparative-animal-respiration/.

Walker, K. (2004). "'Double b(I)ind': peer review and the politics of scholarship." Nursing Philosophy 5: 135-146.

Womack, J. P., et al. (1991). The machine that changed the world: the story of Lean production. How Japan's secret weapon in the global auto wars will revolutionize western industry. New York, Harper Perennial.

Yin, R. K. (2003). Case Study Research: Design and Methods. Thousand Oaks, Sage Publications. 